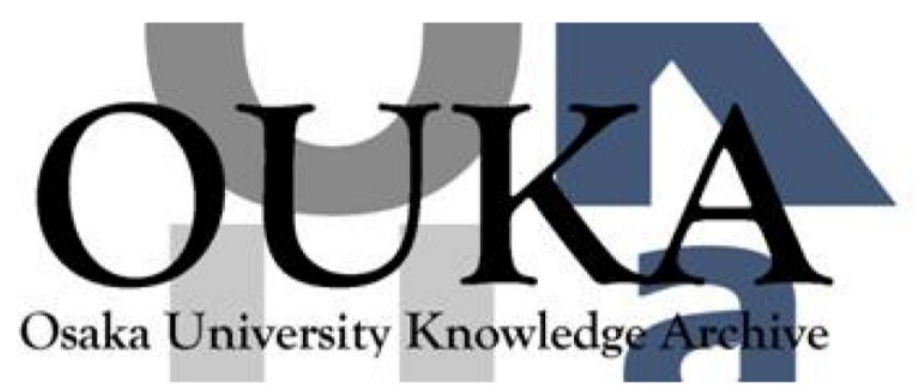

\begin{tabular}{|c|c|}
\hline Title & $\begin{array}{l}\text { Temperature behavior of sound velocity of } \\
\text { fluorine-doped vitreous silica thin films } \\
\text { studied by picosecond ultrasonics }\end{array}$ \\
\hline Author (s) & Nagakubo, A.; Ogi, H.; Ishida, H. et al. \\
\hline Citation & $\begin{array}{l}\text { Journal of Applied Physics. 118(1) p.014307-1- } \\
\text { p. } 014307-8\end{array}$ \\
\hline Issue Date & $2015-07-02$ \\
\hline oaire:version & VoR \\
\hline URL & https://hdl. handle. net/11094/83928 \\
\hline rights & $\begin{array}{l}\text { Copyright } 2015 \text { AIP Publishing LLC. This article } \\
\text { may be downloaded for personal use only. Any } \\
\text { other use requires prior permission of the } \\
\text { author and AIP Publishing. This article } \\
\text { appeared in Journal of Applied Physics, 118(1), } \\
014307,2015 \text { and may be found at } \\
\text { https://doi.org/10.1063/1.4923353. }\end{array}$ \\
\hline Note & \\
\hline
\end{tabular}

Osaka University Knowledge Archive : OUKA

https://ir. Library. osaka-u. ac. jp/

Osaka University 


\title{
Temperature behavior of sound velocity of fluorine-doped vitreous silica thin films studied by picosecond ultrasonics
}

\author{
A. Nagakubo, ${ }^{1}$ H. Ogi, ${ }^{1, a)}$ H. Ishida, ${ }^{1}$ M. Hirao, ${ }^{1}$ T. Yokoyama, ${ }^{2}$ and T. Nishihara ${ }^{2}$ \\ ${ }^{1}$ Graduate School of Engineering Science, Osaka University, Toyonaka, Osaka 560-8531, Japan \\ ${ }^{2}$ Taiyo Yuden Co., LTD., Akashi, Hyogo 674-8555, Japan
}

(Received 17 April 2015; accepted 20 June 2015; published online 2 July 2015)

\begin{abstract}
Vitreous silica $\left(\mathrm{v}-\mathrm{SiO}_{2}\right)$ shows anomalous temperature dependence of velocity, including positive temperature coefficient of velocity (TCV) and velocity minimum around $70 \mathrm{~K}$. The former characteristic allows its application in acoustic-resonator devices as a temperature compensating material. In this paper, we study the temperature dependence of velocity of fluorine-doped $\mathrm{v}-\mathrm{SiO}_{2}$ $\left(\mathrm{v}-\mathrm{SiO}_{2-x} \mathrm{~F}_{x}\right)$ thin films using picosecond ultrasonic spectroscopy. To correct the temperature increase caused by irradiation with light pulses, we calculated the steady temperature increase in the measuring volume with a finite volume method, considering the temperature dependence of thermal conductivity, and find that temperature in the measurement region remains high even when the back surface is cryogenically cooled. Using the corrected temperature, we determine TCV of $\mathrm{v}-\mathrm{SiO}_{2-x} \mathrm{~F}_{x}$ thin films for $0<x<0.264$, which increases as $x$ increases and is smaller than reported bulk values by a factor of $0.5-0.7$. The velocity minimum is absent for the film with $x=0$, but it is clearly observed at $70 \mathrm{~K}$ for the film with the highest fluorine concentration of $x=0.264$. These temperature behaviors are attributed to the change in the $\mathrm{Si}-\mathrm{O}$-Si bond angle caused by the fluorine doping. (C) 2015 AIP Publishing LLC. [http://dx.doi.org/10.1063/1.4923353]
\end{abstract}

\section{INTRODUCTION}

Temperature behaviors of acoustic properties of vitreous silica $\left(\mathrm{v}-\mathrm{SiO}_{2}\right)$ have been studied in wide temperature and frequency ranges, because they are different from usual crystalline materials. While most materials, including crystalline $\mathrm{SiO}_{2}(\alpha$-quartz), show negative temperature coefficients of velocities (TCV), ${ }^{1,2} \mathrm{v}-\mathrm{SiO}_{2}$ shows a positive TCV. Sound velocity $v$ of $\mathrm{v}-\mathrm{SiO}_{2}$ monotonically increases with increasing temperature between 100 and $1800 \mathrm{~K}^{3-8}$ Many studies appear for studying the cause of positive TCV, and this anomaly has been related with the unique structure of $\mathrm{v}-\mathrm{SiO}_{2}$; Krause and Kurkjian measured temperature dependence of $v$ of five types of glasses $\left(\mathrm{SiO}_{2}, \mathrm{GeO}_{2}, \mathrm{BeF}_{2}\right.$, $\mathrm{Zn}\left(\mathrm{PO}_{3}\right)_{2}$, and $\left.\mathrm{B}_{2} \mathrm{O}_{3}\right)$ and observed positive TCVs for materials showing tetrahedrally coordinated structures, whereas $\mathrm{B}_{2} \mathrm{O}_{3}$ showed a negative TCV because of its planar triangle structure, insisting the importance of tetrahedral structure for positive TCV. ${ }^{9}$ Molecular dynamics (MD) simulations indicate that the Si-O-Si bond angle, denoted as $\phi$, is reduced ${ }^{10}$ and the bulk modulus increases ${ }^{11}$ as temperature increases. Our previous result shows that the reduction of $\phi$ causes the stiffened structure in $\mathrm{v}-\mathrm{SiO}_{2} .{ }^{12}$ Therefore, the structural change governed by change in $\phi$ should be highly attributed to the positive TCV.

Previous studies showed that the sound velocity takes a minimum around $70 \mathrm{~K}$, at which attenuation shows a maximum, ${ }^{13-20}$ and the velocity change is attributed to thermally activated relaxation (TAR) of structural defects. ${ }^{14,21-27}$ This velocity minimum is depressed by densification, ${ }^{28,29}$ where

a)ogi@me.es.osaka-u.ac.jp the averaged $\phi$ becomes smaller, yielding the compact membered-ring structure. ${ }^{30}$

Therefore, temperature behavior of sound velocity of $\mathrm{v}-\mathrm{SiO}_{2}$ significantly relates to the structure, especially, to the $\mathrm{Si}-\mathrm{O}-\mathrm{Si}$ bond angle $\phi$. It has been reported that doping fluorine affects the bonding structure of $\mathrm{SiO}_{4}$ tetrahedron ${ }^{31}$ and enhances the positive TCV. ${ }^{32}$ The F-doped vitreous-silica $\left(\mathrm{v}-\mathrm{SiO}_{2-\gamma} \mathrm{F}_{x}\right)$ thin film is then expected for the temperaturecoefficient compensation material in acoustic devices. ${ }^{32}$ The positive TCV of $\mathrm{v}-\mathrm{SiO}_{2}$ is, for example, important for surface acoustic wave filters and film-bulk acoustic resonators to achieve stable operation in a wide temperature range. Therefore, it is important to accurately obtain TCVs of $\mathrm{v}-\mathrm{SiO}_{2-x} \mathrm{~F}_{x}$ thin films for designing acoustic resonators. Because deposited thin films are often composed of nonuniform structures with defects, ${ }^{33}$ temperature behavior of $\mathrm{v}-\mathrm{SiO}_{2-x} \mathrm{~F}_{x}$ thin film should be different from that of the bulk. Thus, we have to measure their TCVs directly.

In this study, we develop picosecond-ultrasound-spectroscopy optics for cryogenic measurements and measure the longitudinal-wave velocity $v$ and $\mathrm{TCV}$ of $\mathrm{v}-\mathrm{SiO}_{2-x} \mathrm{~F}_{x}$ thin films between 10 and $300 \mathrm{~K}$. We use a pure bulk v-SiO specimen $(150 \mu \mathrm{m}$ thick), for comparing its TCV with the thin film, and three $\mathrm{v}-\mathrm{SiO}_{2-x} \mathrm{~F}_{x}$ thin films $(2-4 \mu \mathrm{m}$ thick) for $0<x<0.264$. At room temperature, we measure the refractive index $n$ as well as $v$ of the specimens using the multipleangle picosecond ultrasonics. ${ }^{34}$

In the low temperature measurement, we consider the temperature increase near the specimen surface due to the steady irradiation with light pulses: $\mathrm{v}-\mathrm{SiO}_{2}$ has low thermal conductivity $\kappa$ at room temperature, and it further decreases as temperature decreases. Because the temperature gradient in the specimen is inversely proportional to $\kappa$ (Fourier's 
law), the heated surface remains hot when the specimen is thick. Thus, temperature in the measurement region in picosecond ultrasound near the surface remains higher than the back surface, causing significant difference between the apparent (measured) temperature and actual temperature. Therefore, we perform numerical simulations to calculate the temperature field caused by steady heating with light pulses using a finite volume method, taking account of the temperature dependence of $\kappa$, and corrected the as-measured temperature to deduce accurate TCV.

We found that the pure $\mathrm{v}-\mathrm{SiO}_{2}$ thin film shows a smaller TCV than the bulk. Importantly, it exhibits no velocity minimum although the actual temperature is lower than $30 \mathrm{~K}$, indicating that the thin film has a high-energy structure like densified $\mathrm{v}-\mathrm{SiO}_{2}$. By doping $\mathrm{F}$, TCV of $\mathrm{v}-\mathrm{SiO}_{2-x} \mathrm{~F}_{x}$ thin film increases and the velocity minimum appears. We consider that the bond angle $\phi$ represents the "structural temperature," which governs acoustic properties of $\mathrm{v}-\mathrm{SiO}_{2-x} \mathrm{~F}_{x}$ thin films.

\section{EXPERIMENTAL METHODS}

We used a $150-\mu \mathrm{m}$ thick bulk $\mathrm{v}-\mathrm{SiO}_{2}$ (DAICO MFG CO., LTD.) and synthesized three $\mathrm{v}-\mathrm{SiO}_{2-x} \mathrm{~F}_{x}$ thin films on (100) $\mathrm{Si}$ substrates by the chemical vapor deposition method. ${ }^{32}$ Their fluorine content ratios $x$ are $0,0.114$, and 0.264 , and their film thicknesses are about $4 \mu \mathrm{m}(x=0$ and $0.114)$ and $2 \mu \mathrm{m}(x=0.264)$.

We constructed optics for normal-incident picosecond ultrasonics at cryogenic temperature measurements ${ }^{35}$ and the multi-angle-incident picosecond ultrasonics to measure refractive index $n$ and longitudinal-wave velocity $v$ simultaneously at room temperature as shown in Fig. 1. We used a titanium/sapphire (Ti/S) femtosecond pulse laser, whose repetition rate and wavelength are $80 \mathrm{MHz}$ and $800 \mathrm{~nm}$, respectively. The source light pulse was divided into pump and probe pulses by a polarization beam splitter (PBS). The pump light pulse is modulated by $100 \mathrm{kHz}$ using an acoustooptic crystal modulator (AOM), and the wavelength $\lambda$ of the probe light is converted into $400 \mathrm{~nm}$ using a second harmonic generator (SHG). The delay line was mechanically controlled by corner reflectors on a stepping motor set in the pump light path. The probe light pulse was further divided by a beam splitter (BS) to obtain a reference signal for the balanced detector. The pump and probe light pulses pass the same way after the dichroic mirror (DM), and enter a specimen through a $20 \times$ objective lens, and their powers were about 30 and $20 \mathrm{~mW}$, respectively.

The pump light pulse is absorbed in a $10-\mathrm{nm}$ aluminum thin film deposited on the specimen, exciting a highfrequency strain pulse. The time-delayed probe light reflects and transmits at the surface, and the transmitted light is diffracted by the strain pulse based on Bragg's condition. The reflected and transmitted lights interfere each other, causing the periodic reflectivity change as the strain pulse propagates. $^{12,36}$ This is called Brillouin oscillation, and its frequency $f_{\theta}$ is expressed as

$$
f_{\theta}=\frac{2 v}{\lambda} \sqrt{n^{2}-\sin ^{2} \theta}
$$

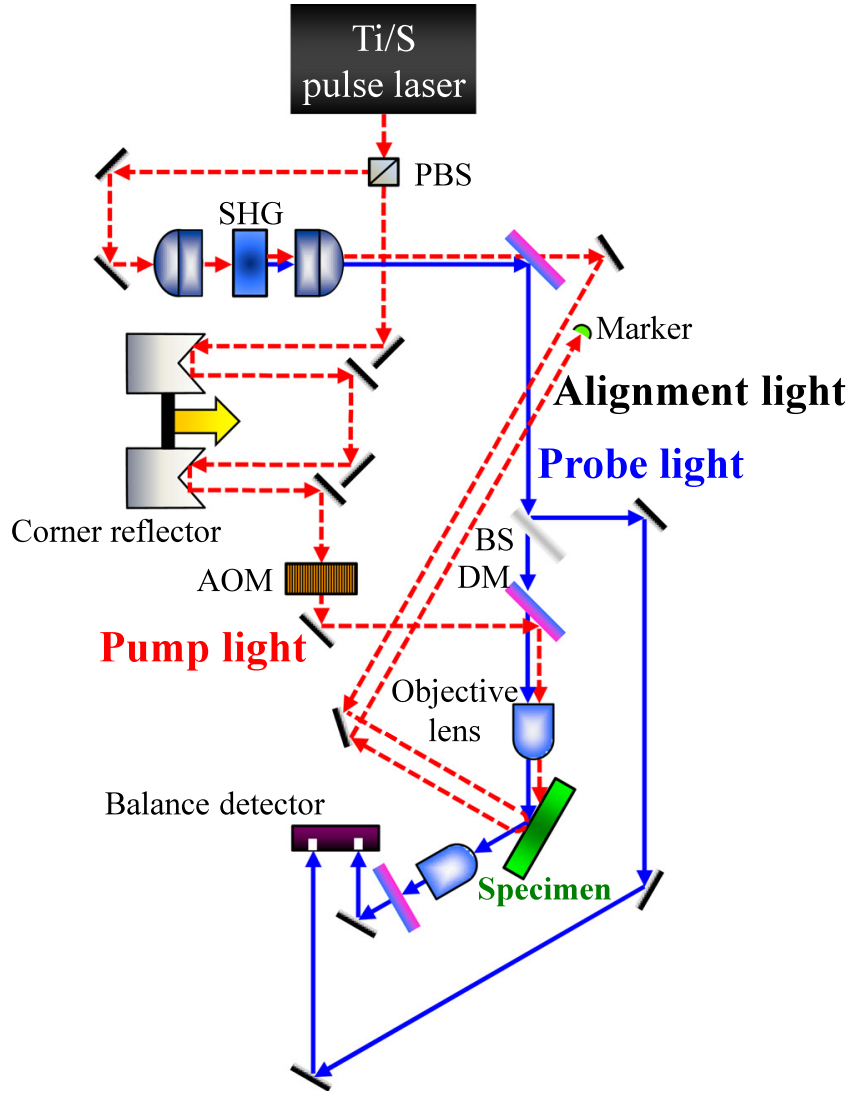

FIG. 1. Multiple-incident optics developed here. Dashed and solid lines represent 800- and 400-nm wavelength lights, respectively. The specimen plane is adjusted using a marker located far away from the specimen.

where $\theta$ is the incident angle of the probe light. $n$ and $v$ are simultaneously obtained by measuring $f_{\theta}$ of different incident angles ${ }^{34}$

$$
\begin{gathered}
v=\frac{\lambda}{2 \sin \theta} \sqrt{f_{0}^{2}-f_{\theta}^{2}}, \\
n=\frac{f_{0} \sin \theta}{\sqrt{f_{0}^{2}-f_{\theta}^{2}}},
\end{gathered}
$$

where $f_{0}$ and $f_{\theta}$ are the Brillouin-oscillation frequencies of normal $(\theta=0)$ and oblique $(\theta \neq 0)$ incidences, respectively.

It is important to measure and maintain the incident angle for accurate measurements of $n$ and $v$. To determine the $\theta$ value, we measured $f_{0}$ and $f_{\theta}$ using a reference specimen of (100) $\mathrm{SrTiO}_{3}$ whose refractive index is measured by the ellipsometry method ${ }^{37}$ using instrument M-2000 produced by J. A. Woollam Co. We then obtain $\theta$ from Eqs. (2) and (3) with known $n$ value. To maintain the incident angle, we normally entered 800 -nm alignment light to the specimen as shown in Fig. 1 and adjusted the specimen plane using a marker located far away from the specimen.

\section{RESULTS AND DISCUSSION}

\section{A. Room temperature measurement}

We show measured Brillouin oscillations and corresponding fast Fourier transformation (FFT) spectra for the 
$\mathrm{SrTiO}_{3}$ reference crystal, the bulk pure $\mathrm{v}-\mathrm{SiO}_{2}$ specimen, and thin-film v-SiO${ }_{2}$ specimens in Fig. 2. The standard deviation (SD) of frequency measured at different points was $0.03 \%$. From the two frequencies measured at different angles, we obtained $v=5966 \pm 4 \mathrm{~m} / \mathrm{s}$ and $n=1.4737$ \pm 0.0002 for the bulk $\mathrm{v}-\mathrm{SiO}_{2}$. These values agree with reported values listed in Table I, confirming reliability of developed optics here. (The static-heating effect discussed in Sec. IIIC is corrected for our values in Table I, although their differences are within $0.3 \%$ at room temperature.)

We performed the measurement for the $\mathrm{v}_{-} \mathrm{SiO}_{2-x} \mathrm{~F}_{x}$ thin films. The results are shown in Table I and Fig. 3. $v$ and $n$ of the $\mathrm{v}_{-} \mathrm{SiO}_{2-x} \mathrm{~F}_{x}$ thin films monotonically decrease as $x$ increases, but $v$ is more sensitive to the doping effect; it decreases by $14 \%$ at $x=0.264$, while $n$ decreases by $2 \%$. Significant differences appear in the velocity between thin films and reported bulk for $\mathrm{v}_{-} \mathrm{SiO}_{2-x} \mathrm{~F}_{x}$ as displayed in Fig. 3, highly indicating that we cannot adopt acoustic properties of a bulk specimen for its thin film even with the same chemical contents.

\section{B. Transient temperature increase by a pump light pulse}

First, we estimate the transient temperature increase by a pump light pulse. A pump light pulse is absorbed in the 10$\mathrm{nm} \mathrm{Al}$ thin film and its temperature increase $\Delta T$ in the film is estimated by ${ }^{40}$

$$
\Delta T=\frac{(1-R) Q}{A \zeta \rho C},
$$

where $Q, A$, and $\zeta$ are power, irradiation area, and penetration depth of the pump light pulse; and $R, \rho$, and $C$ are reflectivity, mass density, and specific heat of the Al film, respectively. In this study, we used the laser spot size of $80 \mu \mathrm{m}$ in diameter. We assumed the uniform laser intensity and $\zeta$ value to be the Al-film thickness $(=10 \mathrm{~nm})$, leading to $\Delta T \sim 0.4 \mathrm{~K}$ at room temperature. However, we have to consider the temperature dependent specific heat to estimate the actual temperature increase in the $\mathrm{Al}$ film because specific heat significantly decreases at low temperatures. ${ }^{41}$ Then, we assumed that the pump light pulse has a Gaussian-shape duration with the half width of the duration time of pulse laser (200 fs) and numerically calculated the temperature increase as follow:

$$
\Delta T=\int_{-\infty}^{\infty} \frac{(1-R)}{A \zeta \rho} \frac{Q(t)}{C(t)} d t
$$

where $t$ denotes time (note that $C$ is a function of time). Thus, obtained temperature dependence of $\Delta T$ are shown in Fig. 4(a). Actually, $\Delta T$ may not be neglected at temperatures below $10 \mathrm{~K}$, but this temperature increase occurs in the $\mathrm{Al}$ thin film, the hottest region, and thermal diffusion into v$\mathrm{SiO}_{2}$ is much slower than the ultrasound: Thermalpenetration depth within a time $t_{0}$ is estimated by $\sqrt{4 D t_{0}}$, where $D=\kappa / \rho C$ is thermal diffusivity. On the other hand, penetration depth of the ultrasound can be determined by $v t_{0}$, which are shown in Fig. 4(b). We found that ultrasound propagates much faster than heat above $10 \mathrm{~K}$. We used Brillouin oscillation data after $50 \mathrm{ps}$ in determining its frequency, and the ultrasonic wave exists near $300 \mathrm{~nm}$ from the surface at this time, whereas thermally affected region is restricted within $30 \mathrm{~nm}$ from the surface even at $10 \mathrm{~K}$ (Fig. 4(b)), indicating that the transient temperature increase will fail to affect our experiments. Therefore, the dynamical temperature increase can be neglected.

Thermal diffusivity also affects the adiabaticity of measurable sound velocity: Usually, elastic deformation by sound occurs adiabatically because thermal diffusion length within a period of the sound wave $1 / f$ is much shorter than the sound-wave wavelength, that is,

$$
\frac{4 D f}{v^{2}} \ll 1 .
$$

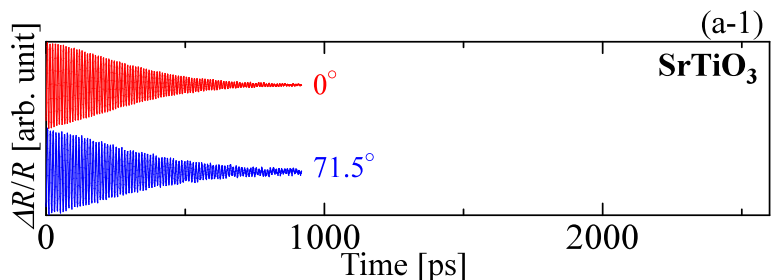

(b-1)

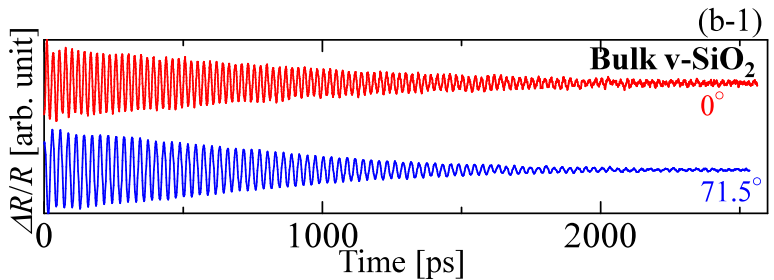

(c-1)

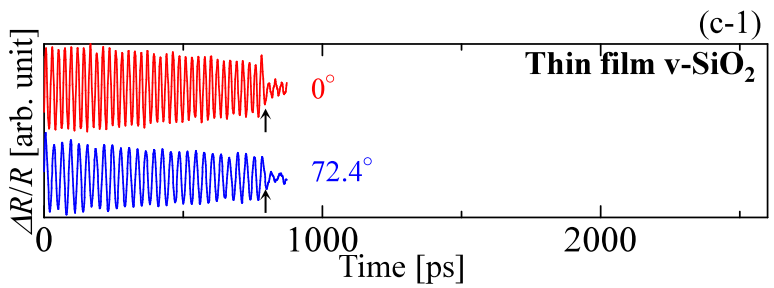

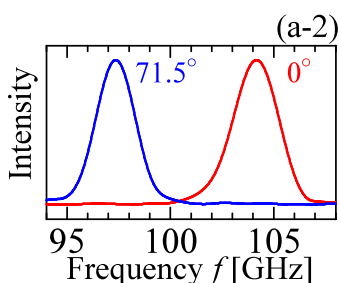

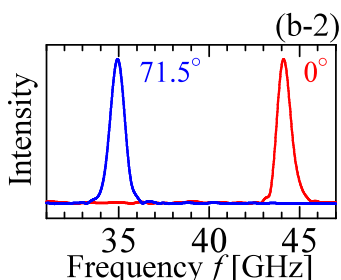

FIG. 2. Observed Brillouin oscillations and corresponding FFT spectra of (a) $\mathrm{SrTiO}_{3}$, (b) bulk v-SiO${ }_{2}$, and (c) thinfilm $\mathrm{v}-\mathrm{SiO}_{2}$ specimens at room temperature. Arrows in (c-1) indicate the film/ substrate interface.

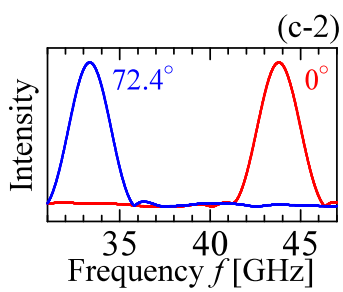


TABLE I. Measured refractive index $n$, longitudinal-wave sound velocity $v$ $(\mathrm{m} / \mathrm{s})$, and temperature coefficient of sound velocity TCV $(\mathrm{ppm} / \mathrm{K})$ of bulk and thin-film $\mathrm{v}-\mathrm{SiO}_{2-x} \mathrm{~F}_{x}$ at room temperature.

\begin{tabular}{lcccc}
\hline \hline Specimen & $x$ & $n$ & $v$ & TCV \\
\hline This work & & & & \\
Bulk & 0 & $1.4737 \pm 0.0002$ & $5966 \pm 4$ & $112 \pm 3$ \\
Film & 0 & $1.4730 \pm 0.0032$ & $5967 \pm 13$ & $70 \pm 10$ \\
Film & 0.114 & $1.4585 \pm 0.0039$ & $5830 \pm 16$ & $86 \pm 4$ \\
Film & 0.264 & $1.4368 \pm 0.0027$ & $5107 \pm 10$ & $164 \pm 24$ \\
Reference & & & & \\
Bulk $^{\mathrm{a}}$ & 0 & 1.4701 & & \\
Bulk $^{\mathrm{b}}$ & 0 & 1.4741 & & \\
Bulk $^{\mathrm{c}}$ & 0 & & 6049 & 98 \\
Bulk $^{\mathrm{c}}$ & 0.018 & & 5959 & 120 \\
Bulk $^{\mathrm{c}}$ & 0.027 & & 5945 & 118 \\
Bulk $^{\mathrm{c}}$ & 0.102 & & 5457 & 157 \\
Bulk $^{\mathrm{d}}$ & 0 & & 5969 & 114 \\
Bulk $^{\mathrm{e}}$ & 0 & & 5943 & 96 \\
Bulk $^{\mathrm{f}}$ & 0 & & 5982 & 108 \\
Bulk $^{\mathrm{g}}$ & 0 & & 5929 & 111 \\
Bulk $^{\mathrm{h}}$ & 0 & & 5953 & 123 \\
Bulk $^{\mathrm{i}}$ & 0 & & 5926 & 129 \\
Bulk $^{\mathrm{j}}$ & 0 & & 5955 & 91 \\
Bulk $^{\mathrm{j}}$ & 0 & & 5976 & 92 \\
Bulk $^{\mathrm{k}}$ & 0 & & 5916 & 93 \\
Bulk $^{1}$ & 0 & & 5969 & 102 \\
Bulk $^{\mathrm{m}}$ & 0 & & 5975 & 101 \\
\hline \hline & & & & \\
\hline
\end{tabular}

${ }^{\mathrm{a}}$ Reference 38 .

${ }^{\mathrm{b}}$ Reference 39.

${ }^{\mathrm{c}}$ Reference 19.

${ }^{\mathrm{d}}$ Reference 4.

${ }^{\mathrm{e}}$ Reference 5 .

${ }^{\mathrm{f}}$ Reference 6.

${ }^{g}$ Reference 7.

${ }^{\mathrm{h}}$ Reference 8 .

${ }^{\mathrm{i}}$ Reference 15

${ }^{\mathrm{j}}$ Reference 18

${ }^{\mathrm{k}}$ Reference 20.

${ }^{1}$ Reference 24

${ }^{\mathrm{m}}$ Reference 29.

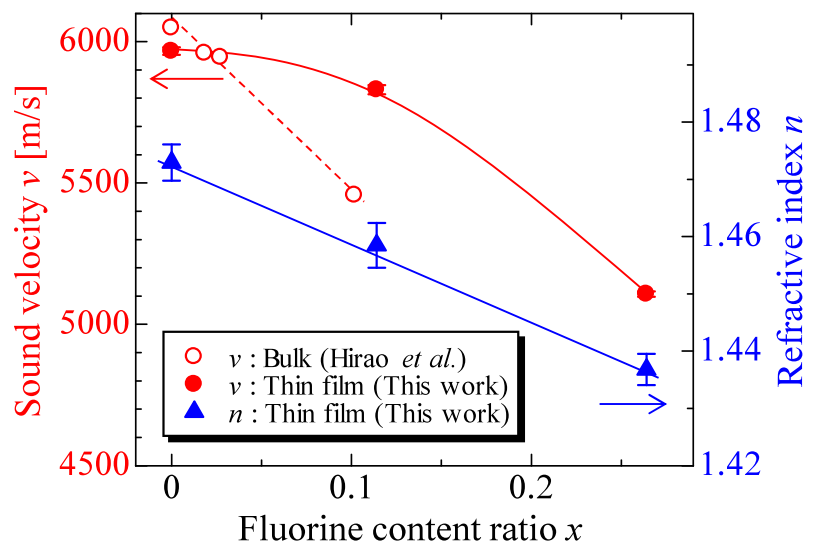

FIG. 3. Fluorine-concentration dependence of sound velocity $v$ and refractive index $n$ at room temperature. Open and solid circles denote $v$ of bulks ${ }^{19}$ and thin films, respectively. Solid triangles denote the refractive index at $400 \mathrm{~nm}$.
Isothermal approximation is then applicable when

$$
\frac{4 D f}{v^{2}} \gg 1
$$

We calculate $4 D f / v^{2}$ for $\mathrm{v}-\mathrm{SiO}_{2}$ between 0 and $300 \mathrm{~K}$ ( $f$ and $v$ are constant to be $43.9 \mathrm{GHz}$ and $5970 \mathrm{~m} / \mathrm{s}$, respectively) as shown in Fig. 4(c). Although we observed high frequency ultrasound, the $4 D f / v^{2}$ value is much smaller than unity and the measured velocity is the adiabatic velocity rather than the isothermal velocity even at $10 \mathrm{~K}$.

\section{Temperature correction with the static heating effect}

The static-heating effect by the repeated light-pulses irradiation was usually neglected in picosecond ultrasonic measurements because of lower laser power and higher thermal conductivity $\kappa$ of a specimen. However, $\mathrm{v}^{-\mathrm{SiO}_{2}}$ shows extremely low $\kappa$, and the static-heating effect would cause non-negligible temperature rise in the measurement region near the heating surface. Especially, this effect becomes remarkable at low temperatures because $\kappa$ of $\mathrm{v}-\mathrm{SiO}_{2}$ decreases markedly with decreasing temperature (it decreases by a factor of 0.1 at $10 \mathrm{~K}$ from room temperature).

We then performed numerical simulations to estimate this effect quantitatively for correcting the apparent (backsurface) temperature $T_{b}$. The axial-symmetric 2D $(r, z)$ equation of heat conduction was numerically solved by the finite volume method. ${ }^{42,43}$ The heat fluxes at the finite volume surface were evaluated by the 2 nd-order central difference scheme, where we incorporated the temperature dependent thermal conductivity reported previously. ${ }^{44} \mathrm{~A}$ local area with radius $r_{0}$ on the front surface $(z=0)$ was heated by uniform or Gaussian heat-flux distribution, and the temperature on the back surface was kept constant. The remaining surface was set to be adiabatic. The radius $r$ of the computation domain was set to $400 \mu \mathrm{m}$ for the specimens whose thicknesses are 2 and $4 \mu \mathrm{m}$. It was, however, $750 \mu \mathrm{m}$ for the $150-\mu \mathrm{m}$ thick specimen. The grids to express the $2 \mathrm{D}$ domain (radius $\times$ height) were $300 \times 60$ for 2 and $4 \mu \mathrm{m}$ thick specimens and $600 \times 120$ for the $150-\mu \mathrm{m}$ thick specimen. The steady state was well confirmed by the fact that the absolute discrepancy between the heat input at a local area on the front surface heated by the irradiation and the heat output on the back surface is less than $10^{-9} \%$.

Figure 5(a) shows the half side of the obtained axialsymmetric temperature fields for $150-$ and $4-\mu \mathrm{m}$ thick $\mathrm{v}-\mathrm{SiO}_{2}$ specimens, when the surface area of $r_{0}=40 \mu \mathrm{m}$ (laser-spot radius) is uniformly heated with $10 \mathrm{~mW}$ energy and the back surface is kept at $50 \mathrm{~K}$. The surface temperature of the $150-\mu \mathrm{m} \mathrm{v}-\mathrm{SiO}_{2}$ specimen exceeds $150 \mathrm{~K}$, and it reaches $66 \mathrm{~K}$ for the $4-\mu \mathrm{m}$ thin-film specimen, indicating that we should calculate the actual temperature $T^{\prime}$ in the measuring volume considering the static-heating effect.

First, to estimate the effects of the heating distribution and temperature dependence of $\kappa$, we performed numerical calculations for following 3 cases for $r_{0}=25 \mu \mathrm{m}$. (We used the radius smaller than that used in the experiments to emphasize these effects.) (i) Uniform heated area and temperature- 


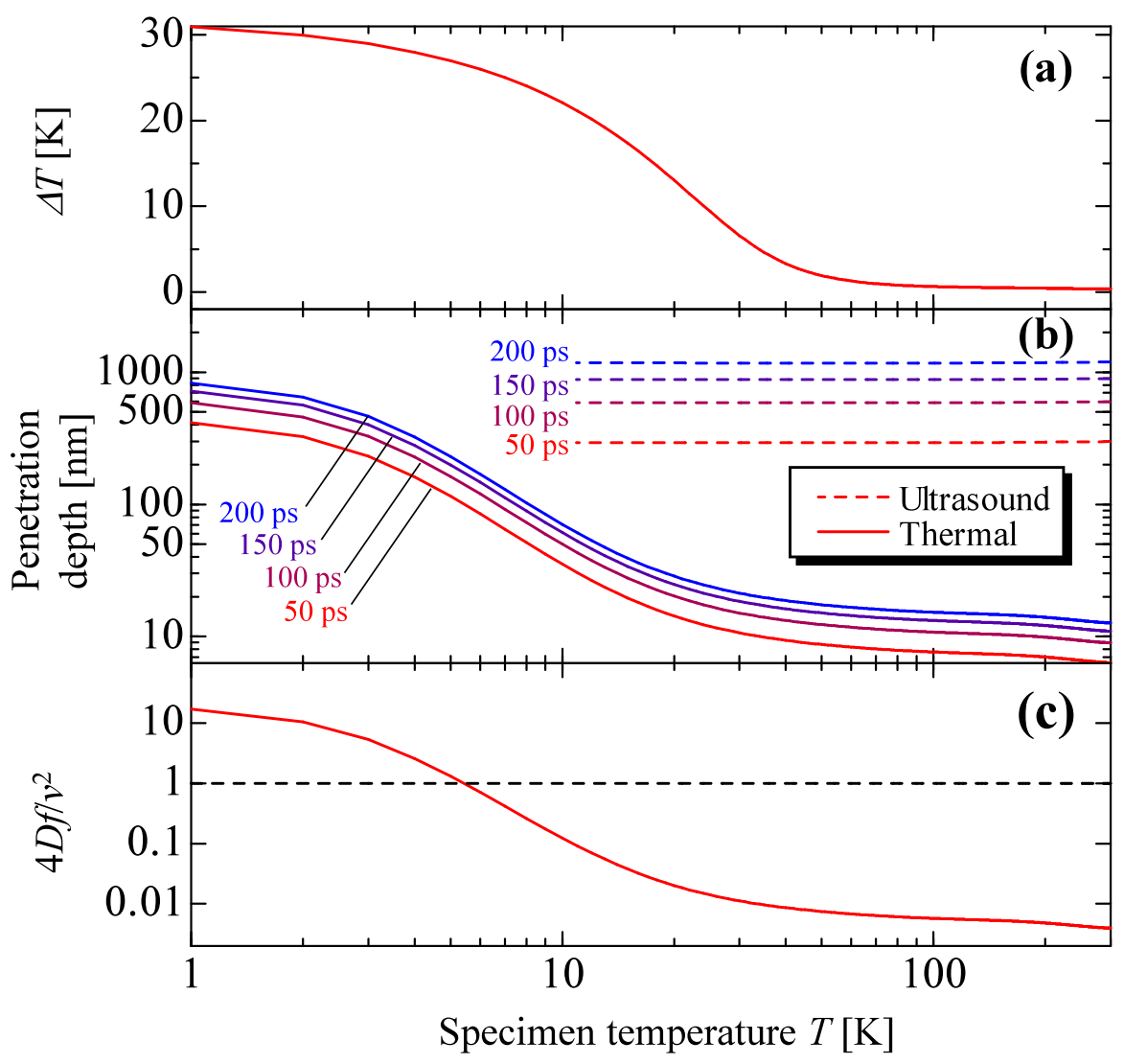

FIG. 4. (a) Temperature increase in $10-\mathrm{nm} \mathrm{Al}$ thin film caused by a $30-\mathrm{mW}$ pump light pulse, where we considered the temperature dependent heatcapacity change during heating with the pulse laser. (b) Temperature dependences of thermal (solid lines) and ultrasonic (dashed lines) penetration depths. (c) Temperature dependence of the adiabaticity index $4 D f / v^{2}$.

independent thermal conductivity ( $\kappa=0.27 \mathrm{~W} / \mathrm{mK}$ at $50 \mathrm{~K}$ ), (ii) uniform heated area and temperature-dependent thermal conductivity, and (iii) Gaussian distribution on the heated area and temperature-dependent thermal conductivity. The total heat energy, back-surface temperature $T_{b}$, and thickness were set to be $10 \mathrm{~mW}, 50 \mathrm{~K}$, and $150 \mu \mathrm{m}$, respectively. Figure 5(b) shows the change of the temperature averaged in the area with $r_{0}=25 \mu \mathrm{m}$ along the depth $z$ direction. Note that the temperature dependence of $\kappa$ have to be involved to estimate the correct temperature distribution, otherwise the temperature increase would be overestimated. The heat-energy distribution little affects the temperature field. We, therefore, performed the numerical calculations considering the temperature dependence of $\kappa$ with uniform distribution.

We thus calculated the averaged temperature within the actual measurement volume with $r_{0}=40 \mu \mathrm{m}$ caused by the static-heating effect. We omitted the Brillouin-oscillation data less than $50 \mathrm{ps}(\sim 300 \mathrm{~nm})$, because resonance signal of the Al film superimposes there. The Brillouin oscillation from the bulk $\mathrm{v}-\mathrm{SiO}_{2}$ is, for example, observed for $1600 \mathrm{ps}$, leading to the penetration depth $z$ of about $10 \mu \mathrm{m}$. We then averaged the calculated temperature in the cylindrical volume with $80-\mu$ m-diameter face between 0.3 and $10 \mu \mathrm{m}$ in this case. We set the input power to be $6.8 \mathrm{~mW}$, which is calculated from pump and probe light's powers and their reflectances to aluminum.

Figures 5(c) and 5(d) show the relationships between the apparent and actual temperatures for the three thickness cases. For the $150-\mu \mathrm{m} \mathrm{v-SiO}, T^{\prime}$ is significantly higher than $T_{b}$, and it exceeds $100 \mathrm{~K}$ at $T_{b}=10 \mathrm{~K}$. On the other hand, $T^{\prime}$ of thin films is nearly the same as $T_{b}$ because of small thicknesses. ( $\mathrm{Si}$ shows much higher $\kappa$ than $\mathrm{v}-\mathrm{SiO}_{2}$ by a factor of $\sim 10000$ at $30 \mathrm{~K},{ }^{45}$ making it possible to assume that the temperature of $\mathrm{Si}$ substrate is the same as the temperature measured on the heat exchanger $\left(T_{b}\right)$, where the thermometer is attached.)

\section{Cryogenic temperature measurement}

We show the measured $v$ of bulk $v-\mathrm{SiO}_{2}$ in Fig. 6 with previously reported values. We used a reported temperature dependence of $n$ to calculate $v{ }^{39}$ (The restriction of the measurement setup prevented us from using the $\theta$ value large enough to deduce a reliable set of $v$ and $n$ in the cryogenictemperature measurements.) The velocity minimum should appear near $70 \mathrm{~K}$, but our measurement failed to find it with the uncorrected temperature $T_{b}$ (solid circles), because the actual specimen temperature did not lower below $100 \mathrm{~K}$ (open circles). Thus, we would have misunderstood the material properties without the proposed temperature correction. We calculated the $\mathrm{TCV}$ of the bulk $\mathrm{v}-\mathrm{SiO}_{2}$ between $200<T^{\prime}<330 \mathrm{~K}$ and obtained $112 \pm 3 \mathrm{ppm} / \mathrm{K}$, which is comparable with reported values in Table I.

Figure 7 shows temperature behaviors of $v$ of $\mathrm{v}_{-} \mathrm{SiO}_{2-x} \mathrm{~F}_{x}$ thin films with reported bulk values measured by Brillouin scattering, ${ }^{18}$ and Fig. 8 compares thin-film TCVs with corresponding bulk TCVs. There are three important observations: (i) The sound-velocity minimum, which normally appears near $70 \mathrm{~K}$ for bulk $\mathrm{v}-\mathrm{SiO}_{2}$, is absent for the film with $x=0$, it seems to be present near $\sim 30 \mathrm{~K}$ for the film with $x=0.114$, and it is clearly observed at $70 \mathrm{~K}$ for the film with the highest $\mathrm{F}$ concentration of $x=0.264$ (Fig. 6). (ii) TCV of a $\mathrm{v}-\mathrm{SiO}_{2-x} \mathrm{~F}_{x}$ film is smaller than the corresponding bulk 

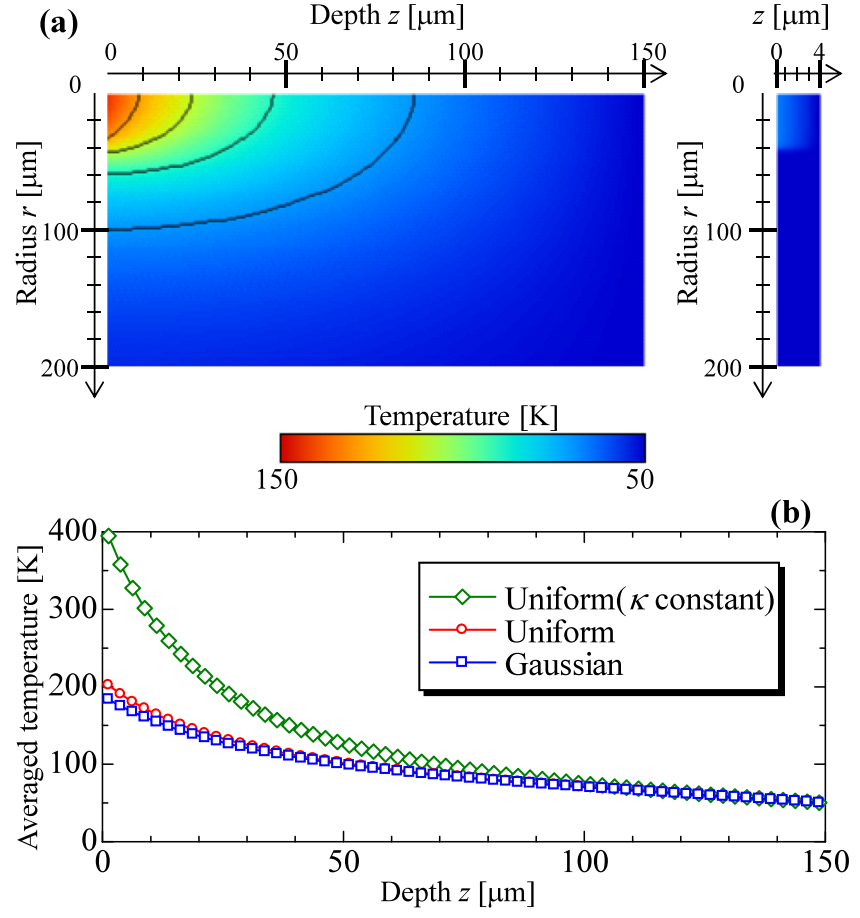

(c)

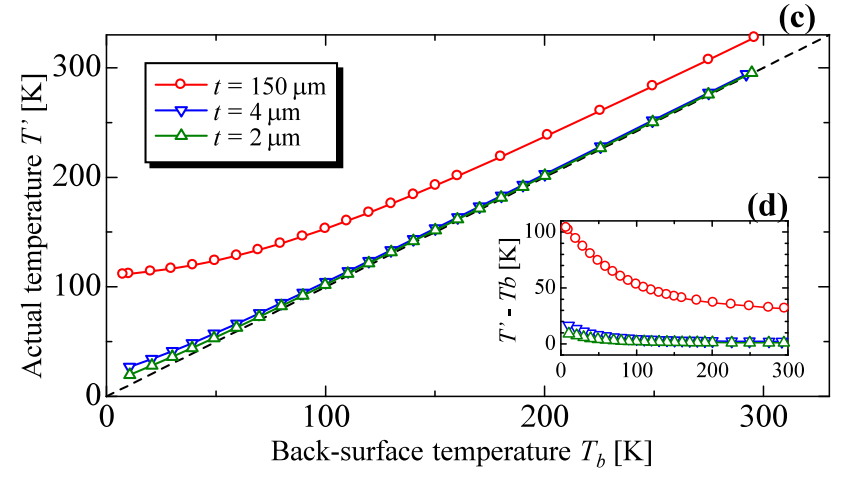

FIG. 5. (a) $2 \mathrm{D}$ temperature distributions of $150-\mu \mathrm{m}$ thick $\mathrm{v}-\mathrm{SiO}_{2}$ (left) and 4- $\mu \mathrm{m}$ thick $\mathrm{v}-\mathrm{SiO}_{2}$ (right) at the back-surface temperature $T_{b}=50 \mathrm{~K}$ when the uniform heat energy of $10 \mathrm{~mW}$ is applied on the surface in a $80-\mu \mathrm{m}$-diameter area. The temperature dependence of thermal conductivity $\kappa$ is involved. The contour lines are shown every $20 \mathrm{~K}$. (b) The thickness distribution of the in-plane averaged temperature in the $50-\mu \mathrm{m}$ diameter for the $150-\mu \mathrm{m}$ thick $\mathrm{v}-\mathrm{SiO}_{2}$ with three cases: (i) uniform heat source neglecting temperature dependence of $\kappa$ (rhomboid), (ii) uniform heat source considering temperature dependence of $\kappa$ (circle), and (iii) Gaussian heat-source distribution considering temperature dependence of $\kappa$ (square). The backsurface temperature is set at $T_{b}=50 \mathrm{~K}$. (c) Relationship between the actual temperature $T^{\prime}$ and the apparent (back-surface) temperature $T_{b}$ for the three specimens with different thicknesses. (d) The temperature increment $T^{\prime}-T_{b}$.

value by $\sim 50 \%$ as shown in Table I and Fig. 8. (iii) TCV increases as the doping concentration increases (Fig. 7).

We intend to explain these observations by high-energy membered-ring structures and averaged $\mathrm{Si}-\mathrm{O}-\mathrm{Si}$ bond angle $\phi$ in thin films. Depositing atoms are quenched on the substrate, resulting in high-energy structures, corresponding to be at high temperature or densified: Polian et al. measured $v$ of bulk v-SiO 2 between 300 and $2200 \mathrm{~K}$ and showed that the TCV decreases as temperature increases. ${ }^{8}$ Döring et al. ${ }^{28}$ and Rat et al. ${ }^{29}$ measured $v$ of densified $\mathrm{v}-\mathrm{SiO}_{2}$ below room temperature, and their TCV values (24 and $58 \mathrm{ppm} / \mathrm{K}$, respectively) are considerably smaller than usual bulk values

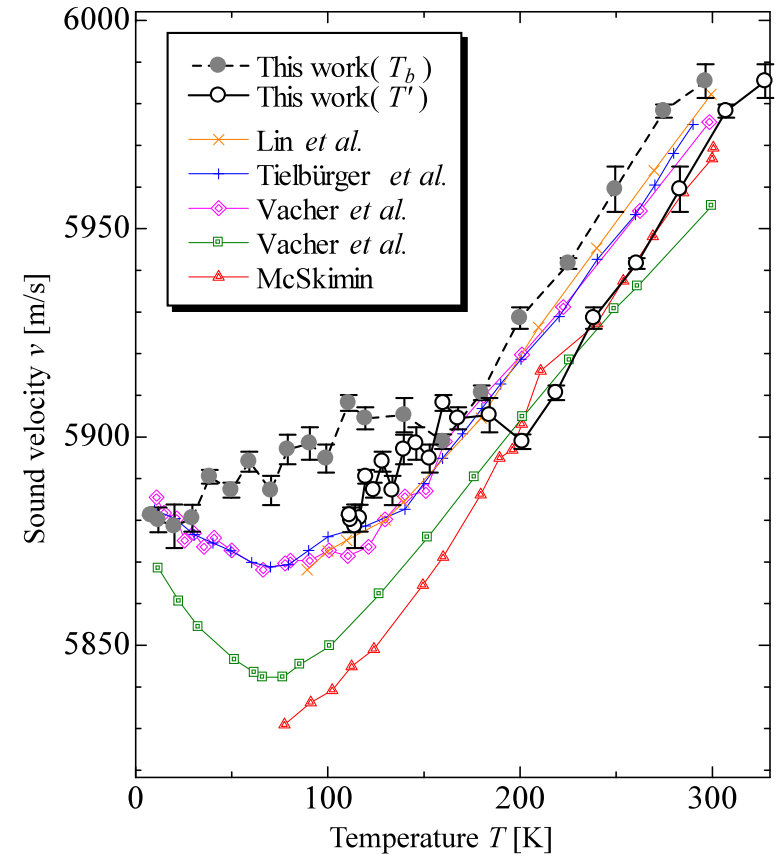

FIG. 6. Comparison of the longitudinal-wave velocity $v$ of bulk $v-\mathrm{SiO}_{2}$ measured in this work with previously reported values. Solid and open circles are our data plotted with the back-surface temperature $T_{b}$ and the actual temperature $T^{\prime}$, respectively. Note that the specimen cannot be cooled down to the velocity-minimum temperature with the picosecond ultrasound measurement. Reference data are from Lin et al., ${ }^{7}$ Tielbürger et al., ${ }^{24}$ Vacher et al., ${ }^{18}$ and McSkimin. ${ }^{4}$

( $\sim 100 \mathrm{ppm} / \mathrm{K})$. Furthermore, Döring et al. observed weakened velocity minimum around $100 \mathrm{~K}$, and Rat et al. found disappearance of the velocity minimum for their densified $\mathrm{v}-\mathrm{SiO}_{2}$ specimens. Our TCV value $(70 \mathrm{ppm} / \mathrm{K})$ for the pure $\mathrm{v}-\mathrm{SiO}_{2}$ thin film corresponds to that of bulk at $900 \mathrm{~K},{ }^{8}$ indicating that the thin film stays in a high-energy structure. An ab-initio calculation predicts that the energy increases with

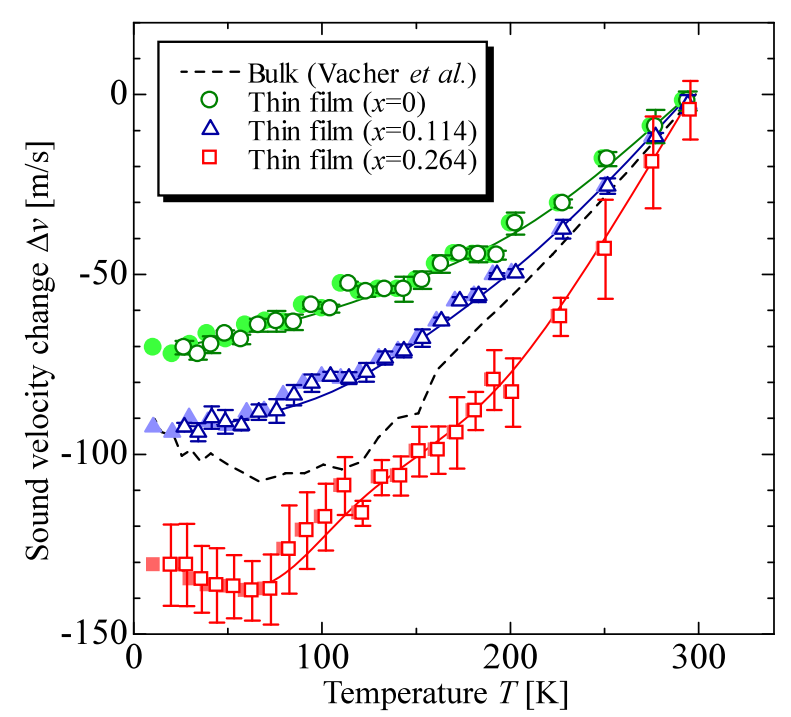

FIG. 7. Temperature dependence of sound velocity $v$ of $\mathrm{v}-\mathrm{SiO}_{2-x} \mathrm{~F}_{x}$ thin films measured in this work. Solid and open symbols are plotted against for the back-surface temperature $T_{b}$ and the actual temperature $T^{\prime}$, respectively. Circle, triangle, and square symbols denote the thin films of fluorine content ratio $x=0,0.114$, and 0.264 , respectively. The dashed line represents a reported bulk value measured by Brillouin scattering. ${ }^{18}$ 


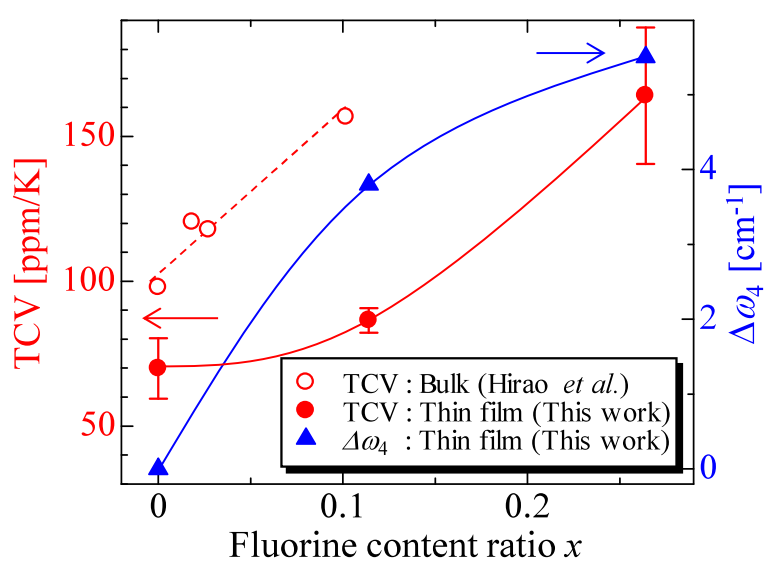

FIG. 8. Fluorine-concentration dependences of TCV and $\Delta \omega_{4}$ of $\mathrm{v}_{-} \mathrm{SiO}_{2-x} \mathrm{~F}_{x}$. Open and solid circles denote TCV of bulks ${ }^{19}$ and thin films, respectively. Solid triangles denote $\Delta \omega_{4}$ of ${\mathrm{v}-\mathrm{SiO}_{2-x}} \mathrm{~F}_{x}$ thin films.

the reduction of the number of the membered ring, ${ }^{46}$ corresponding to the reduction in $\phi$, and an MD simulation shows that the averaged $\phi$ decreases with increasing temperature. ${ }^{10}$ Therefore, the thin-film structure will consist of smaller number of the membered rings with lowered $\phi$. The densified $\mathrm{v}-\mathrm{SiO}_{2}$ is also composed of lowered $\phi$ structures, ${ }^{30}$ and the velocity minimum failed to appear. This may be understood by the higher structural temperature: The structural temperature of the thin film $\mathrm{v}-\mathrm{SiO}_{2}$ as well as the densified $\mathrm{V}-\mathrm{SiO}_{2}$ is high and the cooling them cannot reach the TAR temperature to cause the velocity minimum.

Doping $\mathrm{F}$ divides $\mathrm{Si}-\mathrm{O}-\mathrm{Si}$ bonds, making membered rings and $\phi$ larger. ${ }^{31}$ We measured the absorption peak of so-called $\omega_{4}$ mode ${ }^{47,48}$ by Fourier transform infrared spectroscopy for the $\mathrm{v}-\mathrm{SiO}_{2}{ }_{-x} \mathrm{~F}_{x}$ thin films as shown in Fig. 8. $\omega_{4}$ increases with the amount of fluorine, indicating increased $\phi$ with doping $\mathrm{F}^{49}$ Increase in $\phi$ is consistent with decrease in $v$; in our previous report, we measured $v$ of $\mathrm{v}-\mathrm{SiO}_{2}$ thin films, which decreases with increase in $\phi .{ }^{12}$ Furthermore, MD simulations show that $\phi$ increases as temperature decreases, ${ }^{10}$ which is related to the decrease of $v$ because of the positive TCV. The increase in $\phi$ is also consistent with increase in the TCV: As described above, the larger $\phi$ structure corresponds to the lower structural temperature, and the TCV increases. ${ }^{8}$ Cooling such a material will then cause the TAR, showing the velocity minimum. Therefore, our observation are consistently explained with the change in the $\mathrm{Si}-\mathrm{O}-\mathrm{Si}$ bond angle $\phi$, related to the structural temperature.

\section{CONCLUSIONS}

We developed multi-angle-incident optics to measure the sound velocity $v$ and refractive index $n$ of bulk v-SiO and thin-film $\mathrm{v}-\mathrm{SiO}_{2-x} \mathrm{~F}_{x}$ by picosecond ultrasound spectroscopy. To measure the temperature coefficient of sound velocity, TCV, we performed numerical simulations to obtain the temperature field statically heated by sequential light pulses considering temperature dependence of thermal conductivity $\kappa$, and found that laser absorption significantly increases temperature in the measurement region, which exceeds $100 \mathrm{~K}$ for $150-\mu \mathrm{m} \mathrm{v-SiO}{ }_{2}$ even when back-surface temperature is less than $10 \mathrm{~K}$ because of low $\kappa$ of $\mathrm{v}-\mathrm{SiO}_{2}$. This prevents us from observing the sound velocity minimum around $70 \mathrm{~K}$ by picosecond ultrasound spectroscopy. Using the actual temperature in the measurement region, we determined $\mathrm{v}-\mathrm{SiO}_{2-x} \mathrm{~F}_{x}$ thin films and found that their TCVs are smaller than the corresponding bulk values by more than $30 \%$. The velocity minimum is absent for the pure $\mathrm{v}-\mathrm{SiO}_{2}$ thin film indicating that the film remains the high-energy structure with smaller $\mathrm{Si}-\mathrm{O}-\mathrm{Si}$ bond angle $\phi$ even at cryogenic temperatures, where thermally activated relaxation fails to occur. By doping $\mathrm{F}$, however, $\phi$ becomes larger and the structural temperature lowers, resulting in enhanced TCV and appearance of velocity minimum around $70 \mathrm{~K}$.

\section{ACKNOWLEDGMENTS}

The authors are grateful to Professor Humphrey J. Maris (Brown University) for discussion on the temperature increase by the irradiation of specimen with light pulses.

${ }^{1}$ V. P. Varshni, Phys. Rev. B 2, 3952 (1970).

${ }^{2}$ R. Tarumi, K. Nakamura, H. Ogi, and M. Hirao, J. Appl. Phys. 102, 113508 (2007).

${ }^{3}$ J. W. Marx and J. M. Sivertsen, J. Appl. Phys. 24, 81 (1953).

${ }^{4}$ H. J. McSkimin, J. Appl. Phys. 24, 988 (1953).

${ }^{5}$ S. Spinner, J. Am. Ceram. Soc. 39, 113 (1956).

${ }^{6}$ A. S. Pine, Phys. Rev. 185, 1187 (1969).

${ }^{7}$ H. N. Lin, R. J. Stoner, H. J. Maris, and J. Tauc, J. Appl. Phys. 69, 3816 (1991).

${ }^{8}$ A. Polian, D. V. Thanh, and P. Richet, Europhys. Lett. 57, 375 (2002).

${ }^{9}$ J. T. Krause and C. R. Kurkjian, J. Am. Ceram. Soc. 51, 226 (1968).

${ }^{10}$ K. Yamahara, K. Okazaki, and K. Kawamura, J. Non-Cryst. Solids 291, 32 (2001).

${ }^{11}$ L. Huang and J. Kieffer, Phys. Rev. B 69, 224203 (2004).

${ }^{12}$ H. Ogi, T. Shagawa, N. Nakamura, M. Hirao, H. Odaka, and N. Kihara, Phys. Rev. B 78, 134204 (2008).

${ }^{13}$ M. E. Fine, H. V. Duyne, and N. T. Kenney, J. Appl. Phys. 25, 402 (1954).

${ }^{14}$ O. L. Anderson and H. E. Bömmel, J. Am. Ceram. Soc. 38, 125 (1955).

${ }^{15}$ J. T. Krause, Phys. Lett. 43, 325 (1973).

${ }^{16}$ J. Pelous and R. Vacher, Solid State Commun. 16, 279 (1975).

${ }^{17}$ R. Vacher and J. Pelous, Phys. Rev. B 14, 823 (1976).

${ }^{18}$ R. Vacher, J. Pelous, F. Plicque, and A. Zarembowitch, J. Non-Cryst. Solids 45, 397 (1981).

${ }^{19}$ K. Hirao, T. Kawano, K. Tanaka, and N. Soga, J. Ceram. Soc. Jpn. 99, 600 (1991).

${ }^{20}$ W. Heinicke, G. Winterling, and K. Dransfeld, J. Acoust. Soc. Am. 49, 954 (1971).

${ }^{21}$ R. E. Strakna, Phys. Rev. 123, 2020 (1961).

${ }^{22}$ J. Jäkle, L. Piché, W. Arnold, and S. Hunklinger, J. Non-Cryst. Solids 20, 365 (1976).

${ }^{23}$ K. S. Gilroy and W. A. Phillips, Philos. Mag. A 43, 735 (1981).

${ }^{24}$ D. Tielbürger, R. Merz, R. Ehrenfels, and S. Hunklinger, Phys. Rev. B 45, 2750 (1992).

${ }^{25}$ R. Vacher, E. Courtens, and M. Foret, Phys. Rev. B 72, 214205 (2005).

${ }^{26}$ B. Rufflé, S. Ayrinhac, E. Courtens, R. Vacher, M. Foret, A. Wischnewski, and U. Buchenau, Phys. Rev. Lett. 104, 067402 (2010).

${ }^{27}$ S. Ayrinhac, B. Rufflé, M. Foret, H. Tran, S. Clément, R. Vialla, R. Vacher, J. C. Chervin, P. Munsch, and A. Polian, Phys. Rev. B 84, 024201 (2011).

${ }^{28}$ K. Döring, S. Rau, G. Weiss, J. Arndt, and S. Hunklinger, Phys. Lett. A 184, 464 (1994).

${ }^{29}$ E. Rat, M. Foret, G. Massiera, R. Vialla, M. Arai, R. Vacher, and E. Courtens, Phys. Rev. B 72, 214204 (2005).

${ }^{30}$ S. Susman, K. J. Volin, D. L. Price, M. Grimsditch, J. P. Rino, R. K. Kalia, P. Vashishta, G. Gwanmesia, Y. Wang, and R. C. Liebermann, Phys. Rev. B 43, 1194 (1991).

${ }^{31}$ Y. H. Kim, M. S. Hwang, H. J. Kim, J. Y. Kim, and Y. Lee, J. Appl. Phys. 90, 3367 (2001).

${ }^{32}$ S. Matsuda, M. Hara, M. Miura, T. Matsuda, M. Ueda, Y. Satoh, and K. Hashimoto, Proc. - IEEE Ultrason. Symp. 59, 135 (2012). 
${ }^{33}$ H. Ogi, N. Nakamura, H. Tanei, R. Ikeda, M. Hirao, and M. Takemoto, Appl. Phys. Lett. 86, 231904 (2005).

${ }^{34}$ R. Côte and A. Devos, Rev. Sci. Instrum. 76, 053906 (2005).

${ }^{35}$ A. Nagakubo, A. Yamamoto, K. Tanigaki, H. Ogi, N. Nakamura, and M. Hirao, Jpn. J. Appl. Phys., Part 1 51, 07GA09 (2012).

${ }^{36}$ A. Devos and R. Côte, Phys. Rev. B 70, 125208 (2004).

${ }^{37}$ H. G. Tompkins and W. A. McGahan, Spectroscopic Ellipsometry and Reflectometry (Wiley, New York, 1999).

${ }^{38}$ I. H. Malitson, J. Opt. Soc. Am. 55, 1205 (1965).

${ }^{39}$ J. Matsuoka, N. Kitamura, S. Fujinaga, T. Kitaoka, and H. Yamashita, J. Non-Cryst. Solids 135, 86 (1991).

${ }^{40}$ C. Thomsen, H. T. Grahn, H. J. Maris, and J. Tauc, Phys. Rev. B 34, 4129 (1986).
${ }^{41}$ J. W. Ekin, Experimental Techniques for Low-temperature Measurements (Oxford University Press, Oxford, 2006).

${ }^{42}$ G. D. Smith, Numerical Solution of Partial Differential Equations (Oxford University Press, 1965).

${ }^{43}$ S. V. Patankar, Numerical Heat Transfer and Fluid Flow (Taylor and Francis, 1980).

${ }^{44}$ R. C. Zeller and R. O. Pohl, Phys. Rev. B 4, 2029 (1971).

${ }^{45}$ C. J. Glassbrenner and G. A. Slack, Phys. Rev. 134, A1058 (1964).

${ }^{46}$ D. R. Hamann, Phys. Rev. B 55, 14784 (1997).

${ }^{47}$ P. N. Sen and M. F. Thorpe, Phys. Rev. B 15, 4030 (1977).

${ }^{48}$ F. L. Galeener, Phys. Rev. B 19, 4292 (1979).

${ }^{49}$ A. E. Geissberger and F. L. Galeener, Phys. Rev. B 28, 3266 (1983). 